\title{
Efeito da Temperatura Ambiente sobre o Desempenho de Suínos dos 15 aos $30 \mathrm{~kg}^{1}$
}

\section{Maria Cristina Manno ${ }^{2}$, Rita Flávia Miranda de Oliveira ${ }^{3}$, Juarez Lopes Donzele ${ }^{3}$, Aloízio Soares Ferreira $^{3}$, Will Pereira de Oliveira ${ }^{4}$, Kedson Raul de Souza Lima ${ }^{5}$, Roberta Gomes Marçal Vieira Vaz ${ }^{6}$}

RESUMO - Este trabalho foi conduzido para avaliar o efeito da temperatura ambiente sobre o desempenho, a composição de carcaça e os parâmetros fisiológicos de suínos dos 15 aos $30 \mathrm{~kg}$. Foram utilizados 36 machos castrados (Landrace x Large White), com peso inicial de $14,97 \pm 0,56 \mathrm{~kg}$, distribuídos, durante 23 dias, em delineamento inteiramente casualizado, com três tratamentos, seis repetições e dois animais por unidade experimental. Os tratamentos foram denominados: T1 - animais submetidos a estresse por calor $\left(35^{\circ} \mathrm{C}\right)$, alimentados à vontade; T2 - animais em conforto térmico $\left(22^{\circ} \mathrm{C}\right)$, alimentados à vontade; T3 - animais em conforto térmico $\left(22^{\circ} \mathrm{C}\right)$, com alimentação pareada ao tratamento 1. Foram observadas reduções no consumo de ração, no ganho de peso e no rendimento de carcaça e piora na conversão alimentar, além de queda nas deposições diárias de proteína e gordura nas carcaça dos animais submetidos aos tratamentos 1 e 3, em comparação àqueles do tratamento 2. Os tratamentos não infuenciaram os pesos relativos dos órgãos avaliados, com exceção do peso relativo dos rins e do estômago, que foram menores nos animais do tratamento 1 em relação aos do tratamento 2. Os parâmetros fisiológicos (temperatura retal, temperaturas de superfície de pele e freqüência respiratória) foram influenciados negativamente pela alta temperatura (tratamento 1). Concluiu-se que, dos 15 aos $30 \mathrm{~kg}$, a temperatura ambiente, por meio da redução do consumo de ração, influencia negativamente o ganho de peso, a conversão alimentar e a deposição de proteína na carcaça, além de aumentar a frequência respiratória e a temperatura retal dos suínos.

Palavras-chave: ambiente térmico, carcaça, crescimento, leitões, parâmetros fisiológicos

\section{Effect of Thermal Environment on Performance of Growing Pigs from 15 to $30 \mathrm{~kg}$}

\begin{abstract}
This trial was conducted to evaluate the effect of the environmental temperature on performance, carcass composition and physiological parameters of swine from 15 to $30 \mathrm{~kg}$. Thirty-six barrow (Landrace x Large White) averaging initial weight of $14.97 \pm 0.56 \mathrm{~kg}$ were assigned to a completely randomized experimental design with three treatments and six replicates of two animals. The experimental period lasted 23 days. The treatments were as follows: $\mathrm{T} 1-\operatorname{animals}$ on heat stress $\left(35^{\circ} \mathrm{C}\right)$ fed ad libitum; $\mathrm{T} 2$ - animals on thermal comfort $\left(22^{\circ} \mathrm{C}\right)$ fed ad libitum; T3 - animals on thermal comfort $\left(22^{\circ} \mathrm{C}\right)$, pair feeding with treatment 1. Decreasing effects of treatments 1 and 3 feed intake, weight gain, carcass yield and decrease on feed:gain ratio were observed. It was also observed decrease on daily protein and fat depositions in carcass of the animals of treatments 1 and 3 compared of those in the treatment 2. No effects of treatments on relative weights of evaluated organs were observed, except for the relative weight of kidney and stomach that were smaller in the animals of treatment 1 than those of treatment 2 . The physiological parameters (rectal temperature, surface temperature and respiratory rate) were negatively influenced by high temperature (treatment 1). It was concluded that in the initial phase the environmental temperature by decreasing feed intake, reduce the weight gain, feed:gain ratio, and protein deposition and increase the respiratory rate and rectal temperature of swine.
\end{abstract}

Key Words: carcass, growing phase, physiological parameter, thermal enviroment

\section{Introdução}

A suinocultura brasileira tem desempenhado importante papel no mercado mundial, principalmente em razão dos problemas sanitários ocorridos em outros países grandes produtores e exportadores de carne. Com o objetivo de sempre atender à demanda, a produtividade dos sistemas de criação nacionais tem aumen- tado, sobretudo com o advento de novas tecnologias e com os conhecimentos aprofundados sobre nutrição, fisiologia e sanidade dos suínos.

Entretanto, por ser um país tropical, caracterizado por altas temperaturas, prejudiciais à criação de suínos, o ambiente térmico brasileiro é determinante sobre o sistema produtivo e, muitas vezes, constitui-se no responsável pelo desenvolvimento subótimo do plantel.

\footnotetext{
1 Parte da tese de Mestrado da primeira autora apresentada à UFV.

2Estudante de mestrado, DZO/UFV (mcmanno@uol.com.br).

3 Professor do DZO/UFV (flavia@ufv.br; donzele@ufv.br).

${ }^{4}$ Estudante de graduação em Zootecnia, bolsista de Iniciação Científica (CNPq).

${ }^{5}$ Professor do DZ/UFRA (kedson_lima@uol.com.br).

${ }^{6}$ Estudante de doutorado, DZO/UFV.
} 
Novas pesquisas têm sido desenvolvidas no intuito de se avaliar a intensidade com que o ambiente térmico prejudica o desempenho dos animais.

O conforto térmico ambiental era considerado um problema secundário, tanto do ponto de vista etológico quanto do produtivo. Presumia-se que o desconforto térmico seria resolvido com o uso de condicionamento artificial, sem se considerar os custos e os problemas relacionados à implantação de um sistema climatizado. Porém, segundo Silva (1999), na última década, a preocupação com o conforto térmico animal tem crescido notoriamente, principalmente, quando associada às respostas fisiológicas e aos respectivos índices produtivos.

Como todos os homeotermos, os suínos têm sua temperatura corpórea interna constante. Analisando termodinamicamente, isto significa que precisam trocar calor continuamente com o ambiente. Entretanto, este processo só se mostra eficiente quando a temperatura ambiente está dentro dos limites da termoneutralidade (Hannas, 1999).

Segundo Orlando (2001), suínos mantidos em ambiente termoneutro tendem a expressar seu máximo potencial genético. Porém, quando a temperatura ambiente efetiva aumenta, os animais utilizam mecanismos comportamentais, físicos e químicos que podem levar, conseqüentemente, a um desvio da energia disponível para a produção, modificando a exigência de nutrientes dos animais.

A redução do consumo de ração em animais mantidos em ambiente quente tem sido apontada como o principal componente responsável pela queda no desempenho dos suínos (Fialho et al., 2001). Porém, além dos efeitos da redução do consumo, pode estar envolvido o efeito direto da temperatura sobre a utilização de nutrientes e a produção de calor pelos animais (Collin et al., 2001b). Pouco se sabe sobre o quanto é possível atribuir a queda na produtividade ao consumo de ração, e sobre o ponto a partir do qual a influência é exclusivamente do ambiente.

A fase de desenvolvimento dos suínos também pode influenciar o desempenho em resposta às condições ambientais impostas. Curtis (1983) relatou que suínos pesados têm sido mais sensíveis ao estresse por calor que os mais leves e que o consumo de alimentos por suínos pesando menos de $20 \mathrm{~kg}$ pode ser muito menos influenciado pela temperatura que o de suínos mais velhos, evidenciando que as respostas dos suínos às condições ambientais podem ser dependentes do peso do animal. De acordo com NRC (1981), o peso do animal é altamente correlacionado à porcentagem de gordura corporal e, conseqüentemente, à taxa de perda de calor para o ambiente.

O objetivo neste estudo foi avaliar a influência do ambiente térmico no desempenho, na composição da carcaça e nos parâmetros fisiológicos de suínos dos 15 aos $30 \mathrm{~kg}$.

\section{Material e Métodos}

O experimento foi realizado em salas climatizadas do Laboratório de Bioclimatologia Animal do Departamento de Zootecnia do Centro de Ciências Agrárias da Universidade Federal de Viçosa, em Viçosa, MG.

Foram utilizados 36 suínos machos castrados, mestiços (Landrace x Large White), distribuídos em delineamento experimental inteiramente casualizado, com três tratamentos, seis repetições e dois animais por unidade experimental.

Os tratamentos foram denominados: T1 - ambiente de calor $\left(35^{\circ} \mathrm{C}\right)$ e alimentação à vontade; - T2 ambiente termoneutro $\left(22^{\circ} \mathrm{C}\right)$ e alimentação à vontade; e T3 - ambiente termoneutro $\left(22^{\circ} \mathrm{C}\right)$ e alimentação restrita (equivalente ao consumo à vontade dos animais submetidos ao ambiente de calor - T1). A umidade relativa foi mantida em $71 \%$.

Os animais foram submetidos ao experimento com $14,97 \pm 0,56 \mathrm{~kg}$ e permaneceram por um período pré-determinado de 23 dias.

Para determinação do consumo à vontade nos ambientes de calor e de conforto térmico, a ração fornecida e as sobras (inclusive resíduos) foram pesadas a cada três dias. Em todos os tratamentos, os animais foram pesados a cada seis dias. A ração do tratamento 3 (alimentação pareada) foi fornecida aos animais em duas refeições diárias (manhã e tarde).

Os animais foram mantidos em câmaras climatizadas e alojados em gaiolas metálicas, suspensas, com piso ripado e lateral telada, providas de comedouro semiautomático e bebedouro tipo chupeta.

O ambiente térmico dentro das salas foi monitorado por meio de termômetros de bulbo seco, bulbo úmido e de globo negro, mantidos em uma gaiola vazia, disposta no centro de cada câmara, à meia-altura do corpo dos animais. As leituras dos termômetros foram realizadas diariamente, três vezes ao dia $(8 ; 13$ e $18 \mathrm{~h})$. Os valores registrados foram, posteriormente, utilizados no cálculo do índice de temperatura de globo e umidade (ITGU), segundo Buffington et al. (1981), 
caracterizando o ambiente térmico em que os animais foram mantidos.

Os animais receberam água à vontade e foram alimentados com uma única ração experimental (Tabela 1), à base de milho e farelo de soja, formulada para atender às exigências nutricionais, de acordo com recomendações de Rostagno et al. (2000).

Durante o período experimental, a cada seis dias, foram registradas as temperaturas de superfície de pele (nuca, paleta e pernil traseiro), por meio de termômetro de infravermelho, e a temperatura retal, utilizando-se termômetro clínico introduzido no reto do animal durante um minuto. As freqüências respiratórias foram obtidas pela contagem dos movimentos do flanco dos animais, durante 15 segundos. O resultado foi multiplicado por quatro, para obtenção da freqüência respiratória, em movimentos por minuto.

No final do período experimental (23 dias), após jejum alimentar de 24 horas, um animal de cada unidade experimental, com peso mais próximo de $30 \mathrm{~kg}$, foi abatido por insensibilização e sangramento. Em seguida, procedeu-se à toalete e à abertura da carcaça, para retirada dos órgãos.

Os órgãos foram pendurados à sombra por 20 minutos, para que o sangue escorresse, e, posteriormente, foram pesados. As carcaças foram divididas ao meio e as meia-carcaças direitas, incluindo cabeça e pés, sem vísceras e sangue, foram trituradas por 15 minutos em cutter comercial de $30 \mathrm{HP}$ e 1.775 revoluções por minuto. Após homogeneização do material triturado, foram retiradas amostras das carcaças, que foram estocadas em congelador a $-12^{\circ} \mathrm{C}$.

$\mathrm{Na}$ preparação das amostras para as análises laboratoriais, em razão da alta concentração de gordura do material, procedeu-se à pré-secagem em estufa, com ventilação forçada $\left(60^{\circ} \mathrm{C}\right)$, por 72 horas. Em seguida, foi realizado o pré-desengorduramento, pelo método a quente, por 4 horas.

As amostras pré-secas e pré-desengorduradas foram moídas e acondicionadas em vidros com tampa de polietileno, devidamente identificados, para posteriores análises laboratoriais. Para correção dos valores das análises subseqüentes, foram consideradas a água e a gordura retiradas no preparo das amostras.

As análises de proteína bruta e extrato etéreo das amostras foram realizadas no Laboratório de Nutrição Animal do Departamento de Zootecnia da UFV, de acordo com técnicas descritas por Silva (1990).
Tabela 1 - Composições centesimal e calculada da ração experimental

Table 1 - Ingredient (\%) composition of experimental diets

\begin{tabular}{lc}
\hline $\begin{array}{l}\text { Ingrediente } \\
\text { Ingredient }\end{array}$ & $\begin{array}{c}\text { Quantidade (\%) } \\
\text { Amount }\end{array}$ \\
\hline Milho (Corn grain) & 62,073 \\
Farelo de soja (Soybean meal) & 31,00 \\
Óleo vegetal (Vegetal oil) & 0,752 \\
Fosfato bicálcico (Dicalcium phosphate) & 1,738 \\
Calcário calcítico (Limestone) & 0,732 \\
Sal comum (Salt) & 0,354 \\
Açúcar (Sugar) & 2,984 \\
Mistura mineral (Mineral mix) & 1 \\
Mistura vitamínica (Vitamin mix) & 2 \\
L-lisina-HCl(L-Lysine-HCl) & 0,100 \\
Antibiótico & 0,100 \\
BHT & 0,057 \\
Total & 0,100 \\
\hline
\end{tabular}

Composição calculada ${ }^{3}$

Calculated composition

Proteína bruta (Crude protein), \% $\quad 19,49$

Energia digestível (Digestible energy), $\mathrm{kcal} / \mathrm{kg} \quad 3.400$

Sódio (Sodium), \%

Cálcio (Calcium), \%

0,18

0,83

Lisina total (Total lisyne) $\% \quad 1,03$

Lisina digestível (Digestible lysine), \% $\quad 0,93$

${ }^{1}$ Conteúdo/kg (Content/kg): I- $1.500 \mathrm{mg}$, Co $-1.000 \mathrm{mg}, \mathrm{Cu}-10.000 \mathrm{mg}$ $\mathrm{Zn}-10.000 \mathrm{mg}, \mathrm{Mn}-40.000 \mathrm{mg}$;

${ }^{2}$ Conteúdo/kg (Content $\left./ \mathrm{kg}\right)$ : Vit A - 8.500.000 UI, Vit $\mathrm{D}_{3}-1.300 .000$ $\mathrm{UI}$, Vit E - $20.000 \mathrm{mg}$, Vitamina $\mathrm{K}_{3}-2.000 \mathrm{mg}$, Tiamina (Tiamine) $2.000 \mathrm{mg}$, Riboflavina (Riboflavine) - $5.000 \mathrm{mg}$, Piridoxina (Piridoxine) - $1.600 \mathrm{mg}$, Vitamina $\mathrm{B}_{12}-25.000 \mathrm{mcg}$, Niacina (Niacine) - $40.000 \mathrm{mg}$, Pantotenato de cálcio (Calcium panthotenic) - $15.000 \mathrm{mg}$, Biotina (Biotin) - $120 \mathrm{mg}$, Selênio (Selenium) - $150 \mathrm{mg}$, Antioxidante (Antioxidant) - $30.000 \mathrm{mg}$.

${ }^{3}$ Composição calculada segundo Rostagno et al. (2000).

${ }^{3}$ According to Rostagno et al. (2000) data.

Para determinação da composição corporal dos animais no início do experimento, um grupo adicional de cinco leitões com peso de $14,8 \pm 0,41 \mathrm{~kg}$ foi abatido utilizando-se o mesmo procedimento adotado para o abate dos animais do experimento.

Os valores da composição das carcaças dos leitões no início e fim do período experimental, em cada tratamento, foram considerados para a determinação das deposições diárias de proteína e gordura.

As análises estatísticas das variáveis de desempenho (ganho de peso, consumo e conversão alimentar), de eficiência de utilização de lisina para ganho, de deposições de proteína e gordura nas carcaças, das temperaturas retal e de superfície de pele, da freqüência respiratória e dos pesos dos órgãos foram realizadas utilizando-se o programa computacional SAEG (Sistema para Análises Estatísticas e Genéticas), desenvolvido pela Universidade Federal de Viçosa - UFV (1997). 


\section{Resultados e Discussão}

Os valores de temperatura do ar (T ar), umidade relativa (UR) e índice de temperatura de globo e umidade (ITGU) calculado das salas climatizadas encontram-se na Tabela 2. As temperaturas do ar registradas nos tratamentos de conforto encontram na faixa considerada ideal para suínos em crescimento $\left(22\right.$ a $\left.25^{\circ} \mathrm{C}\right)$, de acordo com Le Dividich (1991). A temperatura do tratamento de calor, no entanto, foi considerada elevada e ultrapassou o limite crítico superior $\left(27^{\circ} \mathrm{C}\right)$ para esta fase, de acordo com Curtis (1983) e Nääs (1989).

Os valores de ITGU obtidos nos tratamentos de conforto térmico deste estudo foram similares aos obtidos por Oliveira et al. (1997), Ferreira (2001) e Vieira Vaz et al. (2005), para leitões machos castrados dos 15 aos $30 \mathrm{~kg}$ (respectivamente, 70,7; 69,6 e $69,5)$. O ITGU obtido para o tratamento de calor $(84,9 \pm 0,72)$ confirma o desconforto ao qual o animal foi submetido pelo aumento da temperatura. Ferreira (2001) e Vieira Vaz (2003) observaram valores semelhantes aos obtidos neste estudo, de 82,6 e 81,2, respectivamente, e consideraram de estresse por calor para suínos na mesma faixa de peso.

Os valores de desempenho e deposição de gordura e proteína dos suínos submetidos aos diferentes tratamentos térmicos dos 15 aos $30 \mathrm{~kg}$ são apresentados na Tabela 3.

Os tratamentos influenciaram $(\mathrm{P}<0,05)$ o consumo de ração dos animais, uma vez que os suínos alojados em ambiente de alta temperatura (T1) consumiram cerca de $12,3 \%$ menos alimento que aqueles alimentados à vontade, em ambiente de conforto térmico (T2). Esse resultado foi semelhante aos

Tabela 2 - Temperatura do ar ( $\mathrm{T}$ ar), umidade relativa (UR) e índice de temperatura de globo e umidade (ITGU) das salas climatizadas

Table 2 - Air temperature (Tair), relative humidity $(R H)$ and black globe humidity index BGHI) of climatizated room

\begin{tabular}{lccc}
\hline $\begin{array}{c}\text { Tratamento } \\
\text { Treatment }\end{array}$ & \multicolumn{3}{c}{$\begin{array}{c}\text { Parâmetro } \\
\text { Parameter }\end{array}$} \\
\cline { 2 - 4 } & $\begin{array}{c}\mathrm{T} \text { ar }\left({ }^{\circ} \mathrm{C}\right) \\
\text { T air }\end{array}$ & $\begin{array}{c}\text { UR }(\%) \\
R H\end{array}$ & $\begin{array}{c}\text { ITGU } \\
\text { BGHI }\end{array}$ \\
\hline Calor & $34,2 \pm 0,75$ & $62,4 \pm 3,10$ & $84,9 \pm 0,72$ \\
Hot & & $71,2 \pm 6,0$ & $71,1 \pm 1,53$ \\
$\begin{array}{l}\text { Conforto } \\
\text { Comfort }\end{array}$ & $22,7 \pm 1,25$ & & \\
\hline
\end{tabular}

encontrados por Le Bellego et al. (2002), que observaram que suínos submetidos a estresse térmico reduziram em torno de $15 \%$ a ingestão diária de alimentos em relação aos animais mantidos em ambiente de conforto $\left(22^{\circ} \mathrm{C}\right)$. Collin et al. (2001a), por sua vez, observaram redução mais acentuada no consumo dos animais (30\%) quando a temperatura ambiente foi ajustada para $33^{\circ} \mathrm{C}$ em relação à de $23^{\circ} \mathrm{C}$.

Diversos autores evidenciaram diminuição do consumo de ração dos animais submetidos a estresse por altas temperaturas (Nienaber et al., 1987; Quiniou et al., 2000; Le Bellego et al., 2002) e relataram que a redução do consumo provavelmente é um mecanismo de defesa para redução da quantidade de calor resultante dos processos digestivos e metabólicos, relacionados principalmente à ingestão de alimentos. Os valores similares de consumo de ração constatados nos tratamentos T1 e T3 evidenciaram a eficiência da proposição de igualar o consumo dos animais.

Constatou-se que os animais submetidos à alta temperatura ambiente (T1) apresentaram redução $(\mathrm{P}<0,05)$ de $22 \%$ no ganho de peso em relação aos animais mantidos em conforto, alimentados à vontade (T2). Avaliando suínos em crescimento (respectivamente, dos 20 aos $30 \mathrm{~kg}$, e dos 23 aos $35 \mathrm{~kg}$ ) mantidos em ambiente de estresse por calor (acima de $29^{\circ} \mathrm{C}$ ) em comparação àqueles mantidos em ambiente termoneutro, Collin et al. (2001a) e Kerr et al. (2003) também observaram redução no ganho de peso diário e na eficiência alimentar com o aumento da temperatura ambiente.

Não se observou $(\mathrm{P}>0,05)$ variação nos valores de ganho de peso entre os animais mantidos sob alta temperatura e os mantidos em conforto térmico que receberam quantidades similares de ração.

A conversão alimentar (CA) dos animais mantidos em conforto térmico (T2) foi 11,5\% menor $(\mathrm{P}<0,05)$ que a dos animais mantidos sob calor (T1), embora em ambos os tratamentos a ração tenha sido fornecida à vontade. Resultados semelhantes foram obtidos por Kerr et al. (2003).

Entretanto, a redução da eficiência de utilização dos alimentos pelos animais mantidos em ambiente quente nem sempre acontece. Oliveira et al. (1997) não encontraram diferenças significativas na eficiência de utilização dos alimentos pelos suínos na mesma faixa de peso mantidos em diferentes ambientes térmicos. Segundo Kerr et al. (2003), as variações de resultados podem estar associadas à 
Tabela 3 - Consumo de ração (CR), ganho de peso (GP), conversão alimentar (CA), consumos de lisina digestível (CLD) e de energia digestível (CED), eficiência de utilização de lisina para ganho (EULG) e deposição de proteína e gordura na carcaça dos suínos, submetidos aos tratamentos dos 15 aos $30 \mathrm{~kg}$

Table 3 - Feed intake (FI), weight gain (WG), feed:gain ratio (F:G), lysine efficiency utilization for gain (LEUG), intake of digestible lysine (IDL) and digestible energy (IDE) and deposition of protein and fat in the carcass of swine on different treatments from 15 to $30 \mathrm{~kg}$

\begin{tabular}{|c|c|c|c|c|}
\hline \multirow[t]{2}{*}{$\begin{array}{l}\text { Parâmetro } \\
\text { Parameter }\end{array}$} & \multicolumn{3}{|c|}{$\begin{array}{c}\text { Tratamento } \\
\text { Treatment }\end{array}$} & \multirow[t]{2}{*}{$\mathrm{CV}(\%)$} \\
\hline & $\begin{array}{c}\text { Estresse por calor e } \\
\text { alimentação à vontade } \\
\text { Heat stress and } \\
\text { ad libitum feeding }\end{array}$ & $\begin{array}{l}\text { Conforto térmico e } \\
\text { alimentação à vontade } \\
\text { Thermal comfort and } \\
\text { ad libitum feeding }\end{array}$ & $\begin{array}{l}\text { Conforto térmico e } \\
\text { alimentação pareada } \\
\text { Thermal comfort } \\
\text { and pair feeding }\end{array}$ & \\
\hline $\mathrm{CR}(F I, k g)$ & $22,84 \pm 1,80 \mathrm{~B}$ & $26,04 \pm 1,33 \mathrm{~A}$ & $21,98 \pm 1,02 \mathrm{~B}$ & 6,06 \\
\hline $\operatorname{CLD}(D L I, g)$ & $212 \pm 16 \mathrm{~B}$ & $242 \pm 12 \mathrm{~A}$ & $204 \pm 9 B$ & 6,37 \\
\hline$C E D(D E I$, kcal $)$ & $77.641 \pm 6.110 \mathrm{~B}$ & $88.543 \pm 4.506 \mathrm{~A}$ & $74.743 \pm 3.470 \mathrm{~B}$ & 6,37 \\
\hline EULG (ganho/g lis) & $56,1 \pm 3,4 \mathrm{~B}$ & $63,1 \pm 1,9 \mathrm{~A}$ & $56,2 \pm 0,9 \mathrm{~B}$ & 3,84 \\
\hline \multicolumn{5}{|l|}{$L E U G($ gain/g lys $)$} \\
\hline \multicolumn{5}{|c|}{ Deposição na carcaça (g/dia) } \\
\hline
\end{tabular}

Médias, na mesma linha, seguidas de letra diferente, diferem estatisticamente entre si $(P<0,05)$ pelo teste SNK.

Means followed by different capital letters within a row are different $(P<0.05)$ by SNK test.

intensidade com que ocorreu a redução na ingestão de alimentos.

A conversão alimentar dos animais que receberam quantidades de ração similares e foram mantidos em ambiente de conforto térmico (T3) e calor (T1) não variou $(\mathrm{P}>0,05)$. Os resultados similares de ganho de peso (GP) e conversão alimentar (CA) verificados entre os animais submetidos a esses dois tratamentos evidenciaram que os efeitos da alta temperatura sobre o desempenho de suínos machos castrados na fase de crescimento (15 a $30 \mathrm{~kg})$ estariam restritos à redução do consumo de ração.

Os consumos de lisina (CLD) e de energia digestíveis (CED) verificados entre os tratamentos variaram $(\mathrm{P}<0,05)$ de forma similar ao consumo de alimentos, o que pode ser justificado pelo fato de as rações terem sido isoprotéicas e isoenergéticas.

Quando se analisou a eficiência de utilização de lisina digestível para ganho (EULG), constatou-se que os animais mantidos no tratamento 2, além de terem consumido maior quantidade de lisina, foram $12,3 \%$ mais eficientes $(\mathrm{P}<0,05)$ que aqueles mantidos nos tratamentos 1 e 3 , que não diferiram $(\mathrm{P}>0,05)$ entre si.

Os maiores valores de consumo de lisina e de EULG resultaram em maior $(\mathrm{P}<0,05)$ deposição de proteína (DP) na carcaça dos animais mantidos no tratamento 2 em relação àqueles submetidos aos demais tratamentos, cujas DP não variaram $(\mathrm{P}>0,05)$.

Considerando a similaridade dos resultados de deposição de proteína entre os animais submetidos aos tratamentos 1 e 3, pode-se inferir que, em suínos nessa fase de desenvolvimento (15 a $30 \mathrm{~kg}$ ), o efeito da alta temperatura sobre a DP se restringiu à redução do consumo de ração. Essa afirmativa corrobora os relatos de Kerr et al. (2003), que associaram a redução na deposição de proteína na carcaça de animais mantidos sob alta temperatura à diminuição no consumo de ração, em relação aos mantidos em conforto térmico.

A deposição de gordura (DG) na carcaça dos animais variou $(\mathrm{P}<0,05)$ diretamente em razão do consumo de energia digestível, de modo que os animais do tratamento 2 apresentaram valor maior $(\mathrm{P}<0,05)$ que os dos demais tratamentos. Estes resultados são semelhantes aos reportados por Collin et al. (2001b), que observaram menor retenção de energia na forma de proteína e gordura em animais com menor consumo de ração $\left(33^{\circ} \mathrm{C}\right.$, com alimentação à vontade; e $23^{\circ} \mathrm{C}$, com alimentação pareada) em relação àqueles mantidos em ambiente de conforto térmico, com alimentação à vontade.

Os resultados de DP e DG na carcaça dos animais, observados entre os tratamentos 1 e 3 divergem 
Tabela 4 - Peso de jejum (PJ), peso de carcaça (PC), rendimento de carcaça (RC), pesos relativos de estômago, de fígado, de rins e de intestino delgado dos suínos submetidos aos tratamentos dos 15 aos $30 \mathrm{~kg}$

Table 4 - Fasting weight (FW), carcass weight (CW), carcass yield (CY), and relative weights of stomach, liver, kidney and gut of swine on different treatments from 15 to $30 \mathrm{~kg}$

\begin{tabular}{|c|c|c|c|c|}
\hline \multirow[t]{2}{*}{$\begin{array}{l}\text { Parâmetro } \\
\text { Parameter }\end{array}$} & \multicolumn{3}{|c|}{$\begin{array}{c}\text { Tratamento } \\
\text { Treatment }\end{array}$} & \multirow[t]{2}{*}{$\mathrm{CV}(\%)$} \\
\hline & $\begin{array}{l}\text { Estresse por calor e } \\
\text { alimentação à vontade } \\
\text { Heat stress and ad } \\
\text { libitumfeeding }\end{array}$ & $\begin{array}{l}\text { Conforto térmico e } \\
\text { alimentação à vontade } \\
\text { Thermal comfort } \\
\text { and ad libitum feeding }\end{array}$ & $\begin{array}{l}\text { Conforto térmico e } \\
\text { alimentação pareada } \\
\text { Thermal comfort } \\
\text { and pair feeding }\end{array}$ & \\
\hline $\mathrm{PJ}(F W, k g)$ & $24,88 \pm 1,54 \mathrm{~B}$ & $27,73 \pm 0,78 \mathrm{~A}$ & $24,26 \pm 1,73 \mathrm{~B}$ & 5,39 \\
\hline $\mathrm{RC}(C Y, \%)$ & $71,96 \pm 1,87 \mathrm{~B}$ & $75,41 \pm 0,84 \mathrm{~A}$ & $72,69 \pm 1,03 \mathrm{~B}$ & 1,80 \\
\hline \multicolumn{5}{|c|}{ Peso relativo (Relative weight, \%) } \\
\hline Estômago (Stomach, \%) & $0,70 \pm 0,05 \mathrm{C}$ & $0,78 \pm 0,02 \mathrm{~B}$ & $0,87 \pm 0,07 \mathrm{~A}$ & 5,94 \\
\hline Fígado (Liver, \%) & $2,64 \pm 0,25 \mathrm{~A}$ & $2,57 \pm 0,21 \mathrm{~A}$ & $2,70 \pm 0,22 \mathrm{~A}$ & 8,60 \\
\hline Rins (Kidney, \%) & $0,47 \pm 0,03 \mathrm{~B}$ & $0,55 \pm 0,03 \mathrm{~A}$ & $0,51 \pm 0,06 \mathrm{AB}$ & 8,66 \\
\hline Intestino delgado (Gut, \%) & $3,64 \pm 0,31 \mathrm{~A}$ & $3,42 \pm 0,21 \mathrm{~A}$ & $3,64 \pm 0,25 \mathrm{~A}$ & 7,29 \\
\hline
\end{tabular}

Médias, na mesma linha, seguidas de letra diferente, diferem estatisticamente entre si $(\mathrm{P}<0,05)$, pelo teste SNK.

Means followed by different capital letters within a row differ $(P<0.05)$ by SNK test.

das proposições do NRC (1981) e de Curtis (1983) de que animais expostos ao calor apresentam menor exigência de mantença que aqueles mantidos em ambiente termoneutro.

Os dados de peso de jejum (PJ), peso de carcaça (PC), rendimento de carcaça (RC) e pesos relativos de órgãos metabolicamente ativos, como estômago, intestino delgado, fígado e rins, dos animais submetidos aos diferentes tratamentos encontram-se na Tabela 4.

Os animais expostos ao ambiente de conforto térmico que receberam alimentação à vontade (T2) apresentaram maiores $(\mathrm{P}<0,05)$ valores de peso de jejum e de carcaça e maior rendimento de carcaça que os submetidos aos demais tratamentos. O maior consumo de lisina e, conseqüentemente, a maior deposição de proteína na carcaça dos animais submetidos ao tratamento 2 justificam os resultados obtidos.

$\mathrm{O}$ fato de não ter ocorrido diferença $(\mathrm{P}>0,05)$ nos valores de PJ, PC e RC entre os animais dos tratamentos 1 e 3 possibilitou inferir que a redução nos valores desses parâmetros, observados nos animais expostos ao estresse por calor em relação ao dos animais que receberam alimentação à vontade no ambiente termoneutro, estaria relacionada ao efeito da alta temperatura sobre o consumo de ração.

Quanto aos pesos relativos dos órgãos, não se observou variação $(\mathrm{P}>0,05)$ entre os tratamentos para pesos do intestino delgado e do fígado dos animais. Por outro lado, os suínos expostos ao ambiente de alta temperatura apresentaram menores
$(\mathrm{P}<0,05)$ valores de peso do estômago que aqueles dos demais tratamentos. Os animais mantidos em conforto térmico que receberam alimentação pareada à dos expostos ao calor apresentaram maior $(\mathrm{P}<0,05)$ peso relativo de estômago, enquanto os que receberam alimentação à vontade no ambiente termoneutro apresentaram maior $(\mathrm{P}<0,05)$ peso relativo de rins.

Esses resultados diferem daqueles obtidos por Oliveira et al. (1997), que, avaliando o efeito da alta temperatura sobre o desempenho e os órgãos de suínos na fase inicial de crescimento, verificaram redução significativa nos pesos relativos de todos os órgãos avaliados (fígado, pulmão e rins) em relação aos dos animais mantidos em ambiente termoneutro com alimentação à vontade.

Portanto, uma vez que as vísceras e os órgãos metabolicamente ativos são os componentes que mais contribuem com o maior percentual da produção de calor total do animal (Koong et al., 1982; Van Milgen et al., 1998), a resposta mais consistente seria a redução de seus pesos relativos nos animais expostos ao calor.

Considerando-se o efeito calorigênico das vísceras e dos órgãos e a relação direta entre a produção de calor metabólica e a exigência de mantença dos animais, o fato de os pesos relativos das vísceras avaliadas e do fígado não terem reduzido nos animais submetidos ao calor e naqueles mantidos em ambiente termoneutro com alimentação pareada pode ter sido determinante para que ocorresse piora na conversão 
Tabela 5 - Freqüência respiratória (FR), temperatura retal ( $T$ retal) e temperaturas de nuca ( $T$ nuca), de paleta ( $T$ paleta) e de pernil (T pernil) dos suínos, submetidos aos tratamentos dos 15 aos $30 \mathrm{~kg}$

Table 5 - Respiratory rate $(R R)$, rectal temperature $(R T)$ and temperatures of nape (Nape T), palette (Palette T) and gammon (Gammon T) of swine on different treatments from 15 to $30 \mathrm{~kg}$

\begin{tabular}{|c|c|c|c|c|}
\hline \multirow[t]{2}{*}{$\begin{array}{l}\text { Parâmetro } \\
\text { Parameter }\end{array}$} & \multicolumn{3}{|c|}{$\begin{array}{c}\text { Tratamento } \\
\text { Treatment }\end{array}$} & \multirow[t]{2}{*}{$\mathrm{CV}(\%)$} \\
\hline & $\begin{array}{l}\text { Estresse por calor e } \\
\text { alimentação à vontade } \\
\text { Heat stress and ad } \\
\text { libitumfeeding }\end{array}$ & $\begin{array}{c}\text { Conforto térmico e } \\
\text { alimentação à vontade } \\
\text { Thermal comfort } \\
\text { and ad libitum feeding }\end{array}$ & $\begin{array}{l}\text { Conforto térmico e } \\
\text { alimentação pareada } \\
\text { Thermal comfort } \\
\text { and pair feeding }\end{array}$ & \\
\hline $\mathrm{FR}(R R$, mov. $/ \mathrm{min})$ & $106 \pm 21 \mathrm{~A}$ & $59 \pm 8 \mathrm{~B}$ & $44 \pm 7 C$ & 19,51 \\
\hline $\mathrm{T}$ nuca (Nape $T^{\circ} \mathrm{C}$ ) & $39,8 \pm 0,88 \mathrm{~A}$ & $36,4 \pm 0,88 \mathrm{~B}$ & $36,4 \pm 0,69 \mathrm{~B}$ & 2,21 \\
\hline T paleta (Palette $T^{\circ} \mathrm{C}$ ) & $39,7 \pm 0,96 \mathrm{~A}$ & $36,2 \pm 1,09 \mathrm{~B}$ & $36,6 \pm 0,87 \mathrm{~B}$ & 2,63 \\
\hline $\mathrm{T}$ pernil (Gammon $\mathrm{T}^{\circ} \mathrm{C}$ ) & $39,6 \pm 1,14 \mathrm{~A}$ & $35,9 \pm 1,23 \mathrm{~B}$ & $36,2 \pm 1,06 \mathrm{~B}$ & 3,09 \\
\hline
\end{tabular}

Médias, na mesma linha, seguidas de letra diferente diferem estatisticamente entre si $(P<0,05)$, pelo teste SNK.

Means followed by different capital letters within a row differ $(P<0.05)$ by SNK test.

alimentar desses animais em relação àqueles mantidos em ambiente termoneutro, alimentados à vontade. Esse relato se confirma pelos resultados obtidos por Oliveira et al. (1997), que não verificaram variação na conversão alimentar dos animais expostos ao calor, os quais tiveram os órgãos diminuídos em relação aos animais mantidos em ambiente termoneutro, alimentados à vontade.

Os efeitos significativos da massa visceral sobre o metabolismo, consumindo aproximadamente $45 \%$ do oxigênio gasto pelo animal, são evidenciados no relato de Nyachoti et al. (2000) de que estratégias de alimentação que visam diminuir o peso desses órgãos podem aumentar a eficiência de conversão de energia e de proteína da ração em ganho na carcaça.

Como não ocorreu variação no peso relativo do intestino delgado e do fígado entre os tratamentos, a redução no consumo de lisina justifica os resultados de menores deposição de proteína e eficiência de utilização de lisina para ganho, observadas nos animais que receberam os tratamentos 1 e 3 em relação aos do tratamento 2 .

Os resultados da freqüência respiratória (FR) e das temperaturas retal e de superfície de pele dos suínos nos diferentes tratamentos são apresentados na Tabela 5. A ocorrência dos maiores $(\mathrm{P}<0,05)$ valores de FR e de temperaturas retal e de superfície no tratamento 1 era esperada, em razão do estresse térmico a que os animais foram propositalmente submetidos. Resultados semelhantes de FR foram também obtidos por Hannas et al. (1999), que observaram número de movimentos $66,7 \%$ superiores nos animais submetidos ao calor em relação àqueles mantidos em conforto térmico.

Os dados de temperatura retal, no entanto, não confirmam aqueles verificados por Oliveira et al. (1997) e Hannas et al. (1999), que não detectaram diferenças significativas na temperatura retal de suínos, na mesma faixa de peso, submetidos ao estresse por calor. A aparente contradição de resultados pode ser justificada pela diferença na intensidade de estresse aplicado, uma vez que esses autores utilizaram uma temperatura ambiental de interesse menor $\left(32^{\circ} \mathrm{C}\right)$ que a utilizada neste estudo $\left(35^{\circ} \mathrm{C}\right)$.

\section{Conclusões}

A alta temperatura ambiente, por meio da redução do consumo de ração, influencia negativamente o ganho de peso, a conversão alimentar e a deposição de proteína, além de aumentar a freqüência respiratória e a temperatura retal de suínos dos 15 aos $30 \mathrm{~kg}$.

\section{Literatura Citada}

BUFFINGTON, D.E.; COLAZZO-AROCHO, A.; CANTON, G.H. et al. Black globe-humidity index (BGHI) as comfort equation for dairy cows. Transactions of the ASAE, v.24, p.711-714, 1981 .

COLLIN, A.; VAN MILGEN, J.; DUBOIS, S. et al. Effect of high temperature on feeding behaviour and heat production in group-housed young pigs. The British Journal of Nutrition, v.86, p.63-70, 2001a.

COLLIN, A.; Van MILGEN, J.; DUBOIS, S. et al. Effect of high temperature and feeding level on energy utilization in piglets. Journal of Animal Science, v.79, p.1849-1857, $2001 \mathrm{~b}$. 
CURTIS, S.E. Environmental managment in animal agriculture. Ames: State University Press, 1983. 409p.

FERREIRA, R.A. Avaliação da redução da proteína bruta da ração com suplementação de aminoácidos para suínos de 15 a $60 \mathrm{~kg}$ mantidos em diferentes ambientes térmicos. Viçosa, MG: Universidade Federal de Viços, 2001. 67p. Tese (Doutorado em Zootecnia) - Universidade Federal de Viçosa, 2001.

FIALHO, E.T.; OST, P.R.; OLIVEIRA, V. Interações ambiente e nutrição - estratégias nutricionais para ambientes quentes e seus efeitos sobre o desempenho e características de carcaça de suínos. In: II Conferência Internacional Virtual sobre Qualidade de Carne Suína, 2001, Concórdia. Acesso em: 12/03/2004. Disponível em: http://www.conferencia.uncnet.br/ pork/seg/palestra.html).

HANNAS, M.I. Aspectos fisiológicos e a produção de suínos em clima quente. In: AMBIÊNCIA E QUALIDADE NA PRODUÇÃO INDUSTRIAL DE SUÍNOS, 1999, Piracicaba. Anais... Piracicaba: Fundação de Estudos Agrários Luiz de Queiroz, 1999. p.01-33.

HANNAS, M.I.; OLIVEIRA, R.F.M.; DONZELE, J.L. et al. Efeito da temperatura ambiente sobre parâmetros fisiológicos e hormonais de leitões dos 15 aos $30 \mathrm{~kg}$. In: REUNIÃO ANUAL DA SOCIEDADE BRASILEIRA DEZOOTECNIA, 36., 1999, Porto Alegre. Anais... Porto Alegre: Sociedade Brasileira de Zootecnia, 1999. 226p.

KERR, B.J.; YEN, J.T.; NIENABER, J.A. et al. Influences of dietary protein level, amino acid supplementation and environment temperature on performance, body composition, organ weights and total heat production of growing pigs. Journal of Animal Science, v.81, p.1998-2007, 2003

KOONG, L.J.; NIENABER, A.; PEKAS, J.C. et al. Effects of plane of nutrition on organ size and fasting heat production in pigs. Journal of Nutrition, v.112, p.1638-1642, 1982.

LE BELLEGO, I.; Van MILGEN, J.; NOBLET, J. Effect of high temperature and low-protein diets on the performance of growing-finishing pigs. Journal of Animal Science, v.80, p.691-701, 2002.

LE DIVIDICH, J.L. Effect of environmental temperature on the performance of intensively reared growing pigs. Selezione Veterinaria, v.32, p.191-207, 1991 (Suppl. 1).

NATIONAL RESEARCH COUNCIL - NRC. Effect of environmental on nutrient requeriments of domestic animals. Washington, D.C.: NRC, NAS, 1981. 52p.

NÄÄS, I.A. Princípios do conforto térmico na produção animal. São Paulo: Ícone, 1989. 183p.

NIENABER, J.A.; HAHN, G.L.; YEN, J.T. Thermal environment effects on growing-finishing swine. Part I Growth, feed intake and heat production. Transactions of the ASAE, v.30, p.1772-1775, 1987.
NYACHOTI, C.M.; DE LANGE, C.F.M.; MCBRIDE, B.W. et al. Dietary influence on organ size and in vitro oxygen consumption by visceral organs of growing pigs. Livestock Production of Science, v.65, p.229-237, 2000.

OLIVEIRA, R.F.M.; DONZELE, J.L.; FREIRAS, R.T.F. et al. Efeito da temperatura ambiente sobre o desempenho e sobre parâmetros fisiológicos e hormonais de leitões consumindo dietas com diferentes níveis de energia digestível. Revista Brasileira de Zootecnia, v.26, p.1173-1182, 1997.

ORLANDO, U.A.D. Nível de proteína bruta da ração e efeito da temperatura ambiente sobre o desempenho e parâmetros fisiológicos de leitoas em crescimento. Viçosa, MG: Universidade Federal de Viçosa, 2001. 77p. Dissertação (Mestrado em Bioclimatologia Animal) - Universidade Federal de Viçosa, 2001.

QUINIOU, N.; DUBOIS, S.; NOBLET, J. Voluntary feed intake and feeding behaviour of group-housed growing pigs are affected by ambient temperature and body weight. Livestock Production Science, v.63, p.245-253, 2000.

ROSTAGNO, H.S.; ALBINO, L.F.T.; DONZELE, J.L. Tabelas brasileiras para aves e suínos. Composição de alimentos $\mathrm{e}$ exigências nutricionais. Viçosa, MG: Universidade Federal de Viçosa, 2000. 141p.

SILVA, D.J. Análise de alimentos: métodos químicos e biológicos. Viçosa, MG: Universidade Federal de Viçosa, 1990. 166p.

SILVA, I.J.O. Qualidade do ambiente e instalações na produção industrial de suínos. In: SIMPÓSIO INTERNACIONAL DE SUINOCULTURA, 4., 1999, São Paulo. Anais... São Paulo: Gessuli, 1999. p.108-121.

UNIVERSIDADE FEDERAL DE VIÇOSA - UFV. Manual de utilização do programa SAEG (Sistema para Análises Estatísticas e Genéticas). Viçosa, MG: 1997. 150p.

Van MILGEN, J.; BERNIER, J.F.; LECOZLER, Y. et al. Major determinants of fasting heat production and energetic cost of activity in growing pigs of different body weight and breed/ castration combination. British Journal of Nutrition, v.79, p.509-517, 1998.

VIEIRA VAZ, R.G.M.; OLIVEIRA, R.F.M.; DONZELE, J.L. Exigência de aminoácidos sulfurados digestíveis para suínos machos castrados mantidos em ambiente termoneutro dos 15 aos $30 \mathrm{~kg}$. Arquivo Brasileiro de Medicina Veterinária, v.57, p.345-352, 2005. 